\title{
UNA NUEVA VARIEDAD DE MYCOPEPON SMITHII (ASCOMYCETES, PLEOSPORALES)
}

\author{
Felipe San Martin Gonzalez \\ Instituto Tecnológico de Ciudad Victoria \\ Apartado Postal 175
}

Cd. Victoria, Tamaulipas

\section{RESUMEN}

Se describe la variedad mexicanum de Mycopepon smithii (Ellis et Everh.) Boise (Ascomycetes, Pleosporales), colectada en el estado de Chiapas, México. El taxon mexicano difiere de la variedad tipo en que presenta pseudotecios y ascosporas más grandes.

\section{ABSTRACT}

The variety mexicanum of Mycopepon smithii (Ellis et Everh.) Boise (Ascomycetes, Pleosporales) collected in the state of Chiapas, Mexico, is described. The Mexican taxon differs from the type variety in having bigger pseudothecia and ascospores.

\section{INTRODUCCION}

Boise (1987) describió de la Guyana Francesa al nuevo género Mycopepon, para acomodar a $M$. guianensis Boise. Posteriormente, descubrió un epíteto previo del hongo, basado en Pseudovalsa smithii Ellis et Everh. (Boise, 1994). El hongo, saprófito y asignable al orden Pleosporales de los Ascomycetes, fue colectado sobre madera descortezada en Monte Galbao, Guyana Francesa y presenta ascocarpos carbonosos superficiales, con 3 - más pseudotecios globosos, confluentes en un cuello común central o excéntrico, que en conjunto dan la apariencia de una calabaza (de ahí la etimología genérica: myco- Gr. = hongo; pepon Gr. = calabaza). Las pseudoparafisas celulares se producen al lado de ascos bitunicados, cilíndrico-clavados, octosporados. Las ascosporas son elipsoides inequilaterales a fusiformes, con extremos agudos, usualmente triseptadas, lisas, de color café.

En 1988, durante un trabajo de campo desarrollado en la Reserva de la Biósfera Montes Azules del Municipio de Ocosingo, Chiapas, el autor colectó un hongo notoriamente similar al descrito por Boise. Al examinar el espécimen se detectaron diferencias con el tipo que ameritan la propuesta de la nueva variedad que aquí se describe. 


\section{METODOLOGIA}

La colecta se hizo sobre madera muerta usando navaja. El material se secó al aire y se guardó en bolsas de plástico junto con una etiqueta con los siguientes datos: localidad, fecha, substrato, tipo de vegetación, colector y su número.

Para identificar el hongo a nivel de especie, se anotaron los siguientes rasgos macroscópicos: forma, dimensiones y color de los ascocarpos y substrato. Con el propósito de estudiar las características microscópicas de los ascocarpos, se tomaron ascos y ascosporas del himenio removiendo la parte superior del ascoma con una navaja, se colocó una gota de agua destilada estéril en la cavidad y se extrajo el material hidratado con una aguja de disección. El contenido himenial se montó en agua destilada estéril y se examinó al microscopio de campo claro o en contraste diferencial de interferencias. Para observar la condición amiloide o inamiloide de los ápices ascales se empleó el reactivo de Melzer. Los siguientes caracteres fueron registrados para 20 ascos: forma y longitud total (incluyendo los pedicelos), disposición y número de ascosporas, presencia o ausencia de endotúnica y grado de tinción de los ápices ascales.

Se analizaron 20 ascosporas de cada ascocarpo registrándose en hojas de datos su forma, color, presencia o ausencia de apéndices, número de septos y sus dimensiones. Los datos se compararon con la descripción provista por Boise (1987).

\section{RESULTADOS}

Al comparar los datos obtenidos del material mexicano con la descripción de Boise, se detectaron diferencias marcadas en el tamaño de los pseudotecios y ascosporas. Los caracteres del espécimen mexicano se describen abajo.

Mycopepon smithii Ellis et Everh. (Boise) var. mexicanum var. nov. Fig. 1. Variedad típica en Mycotaxon 52: 303. 1994.

A varietate typica specie differt ascomatibus majoribus 0.7-1.2 $\mathrm{mm}$ diam et ascosporis (58-)60-84(-95) x 14-16.5(-18.5) micras.

Ascomas sésiles, solitarios, gregarios o fusionados, superficiales o errumpentes a través de fisuras de la madera, de 0.7-1.2 mm de diámetro; con 2-6 lóculos globosos, confluentes, que desembocan en un cuello común central o lateral, de hasta $1 \mathrm{~mm}$ de altura, con un poro apical. Textura carbonosa. Superficie lisa, exceptuando la parte apical del cuello de algunos ascomas que presentan un crecimiento algo hirsuto (¿parásito?) de color café ferruginoso, que consiste en cerdas septadas con la base inflada. Exterior negro, interior blanquecino-ceroso. Pseudoparafisas celulares, simples o ramificadas di 0 tricotómicamente. Ascos cilíndricos, bitunicados, anchos, con ocho ascosporas en un arreglo biseriado, inamiloides, sin poro apical, 194-246 micras de longitud total x 25-32 micras de ancho, 170-210 micras en la parte esprígena. Ascosporas elipsoides inequilaterales a naviculares, cafés a cafés obscuras, usualmente triseptadas, raramente biseptadas, algo constreñidas al centro, (58-)60-84(-95) micras de largo x 14-16.5(-18.5) micras de ancho, con extremos agudos y a veces constreñidos. 

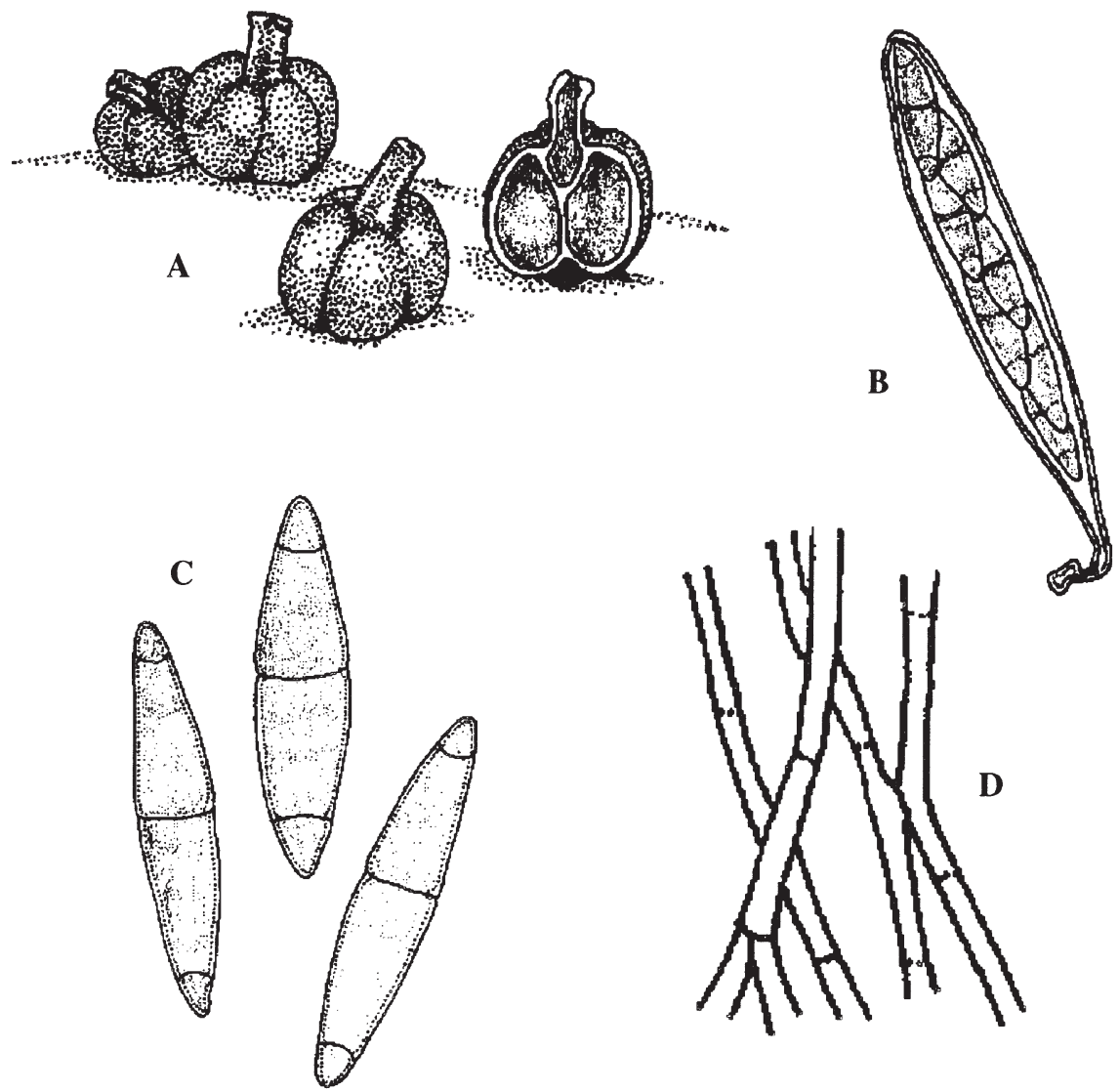

Fig. 1. Mycopepon smithii var. mexicanum. A. Ascomas, $1 \mathrm{~cm}=0.7 \mathrm{~mm}$; B. Asco bitunicado octosporado, $1 \mathrm{~cm}=36 \mu \mathrm{m}$; C. Ascosporas triseptadas, $1 \mathrm{~cm}=17.5 \mu \mathrm{m}$; D. Pseudoparafisas celulares, $1 \mathrm{~mm}=0.7$ $\mu \mathrm{m}$.

Holotipo: México, estado de Chiapas, municipio de Ocosingo, Reserva de la Biosfera Montes Azules, sobre madera descortezada en una selva alta perennifolia, 28.V.1988, San Martín 869B, (ITCV).

La variedad mexicanum difiere de la típica en que presenta pseudotecios más grandes i.e. $0.7-1.2 \mathrm{~mm}$ de diámetro vs $0.5 \mathrm{~mm}$ de diámetro, y ascosporas mayores i.e. (58-)60-84(-95) micras de largo x 14-16.5(-18.5) micras de ancho vs 30-65 micras de largo x 6-16 micras de ancho. 
La presencia de Mycopepon de ascos bitunicados entre pseudoparafisas, claramente lo ubica dentro del orden Pleosporales de los Loculoascomycetes sensu Barr (1979) o de los Dothideales sensu Arx y Müller (1975). Según Boise (1987), el hongo no puede ser asignado ahora a ninguna familia dados los constantes cambios taxonómicos dentro de Pleosporales. Eriksson y Hawksworth (1987) consideran que el género puede colocarse tentativamente en Melanommataceae de los Ascomycetes bitunicados.

\section{AGRADECIMIENTOS}

El autor patentiza su agradecimiento al Biólogo Jorge Ayala Guajardo, por su gentileza y ayuda durante el trabajo de campo en Chiapas. Asimismo, al Dr. Jack D. Rogers, por fungir como árbitro al revisar el escrito y llamar nuestra atención sobre el artículo de 1994 de Jean Boise.

\section{LITERATURA CITADA}

Arx, J. A. von y E. Müller. 1975. A re-evaluation of the bitunicate ascomycetes with keys to families and genera. Stud. Mycol. 9: 1-159.

Barr, M. E. 1979. A classification of Loculoascomycetes. Mycologia 71: 935-957.

Boise, J. R. 1987. Mycopepon, a new ascomycete genus. Systema Ascomycetum 6: 167-170.

Boise, J. R. 1994. Pseudovalsa smithii is an earlier name for Mycopepon guianensis. Mycotaxon 52: 303.

Eriksson, O. y D. L. Hawksworth. 1987. Notes on ascomycete systematics. Systema Ascomycetum 6: 111-165. 